\section{Religious cliché and COVID-19 management: a barrier for physicians}

The COVID-19 pandemic is a global crisis and efforts are focused concomitantly on limiting the transmission and reducing the impact of the virus. ${ }^{1}$ From hand hygiene to vaccine development, physicians around the globe are trying to explore an effective and efficient disease management protocol. However, as with every other disease, COVID-19 has developed a religious cliché that has created a barrier for physicians in disease management. Especially in the developing world, practices are observed that are resulting in avoidance of precautionary measures as proposed by physicians. One example is the attitude of some Islamic faith believers who are not following the recommended precautions against COVID-19.2 On being questioned, it has been quoted that, 'Allah is sufficient for us; and what an excellent guardian He is. ${ }^{3}$ Additionally, the prevailing belief of life and death being controlled by the Almighty ${ }^{4}$ is also becoming a religious stigma in adopting precautionary measures. Moreover, drinking cow urine and hosting cow urine drinking parties to cure Coronarelated illness is also reported. ${ }^{5,6}$ Combining and consuming water and sacred soil found at the grave of Maronite monk Mar Charbel (Mount Lebanon) is also practised against COVID-19. ' We agree that religion is part of the human make-up and faith healing exists in societies as a prime philosophy. Today, people are looking to religion for COVID-19 protection but by doing so are not following the basic precautionary measures, and that is a barrier faced by the frontliners against COVID-19.

One possible solution to this religious cliché is to engage the religious leaders of the respective societies. These leaders are the most respected figures in communities and the influence on their followers can greatly benefit the efforts against COVID19. As community members listen to their religious leaders, physicians should take them on board while handling and managing COVID-19, both in hospitals and at a communal level. Because religious leaders influence social values, practices, and beliefs with their faith-based teachings, we strongly believe that their role in preventing COVID-19 will augment the efforts of the physicians. COVID-19 is a pandemic catastrophe and it is high time to overcome the religious cliché that is becoming a barrier for physicians in the optimal management of COVID-19.

Qaiser lqbal,

University of Balochistan, Quetta, Pakistan.

Abdul Malik Tareen,

University of Balochistan, Quetta, Pakistan.

Fahad Saleem,

University of Balochistan, Quetta, Pakistan. Email: fahaduoblagmail.com

\section{REFERENCES}

1. World Health Organization. Report of the WHO China joint mission on coronavirus disease 2019 [COVID-19]. 2020. https://www.who.int/docs/ default-source/coronaviruse/who-china-jointmission-on-covid-19-final-report.pdf laccessed 7 May 2020)

2. World Health Organization. Coronavirus disease (COVID-19) advice for the public. 2020. https:// www.who.int/emergencies/diseases/novelcoronavirus-2019/advice-for-public laccessed 7 May 2020)

3. The Noble Qur’an. Surah Ali 'Imran 3:173. Pro Bono Project, 2016

4. The Noble Qur'an. Surah Ali 'Imran 3:156. Pro Bono Project, 2016.

5. Morris C. Coronavirus: more myths to ignore. $B B C$ News 2020; 23 Mar: https://www.bbc.co.uk/news/ av/51979410/coronavirus-more-myths-to-ignore (accessed 7 May 2020).

6. Irish J. Coronavirus: Hindu group hosts 'cow urine drinking party' to cure illness despite lack of evidence. Independent 2020; 14 Mar: https:// www.independent.co.uk/news/world/asia/ coronavirus-news-hindu-cow-urine-drinkingparty-india-a9402491.html (accessed 7 May 2020).

7. Darwish R. Sacred soil, cow urine and other rituals: people turn to religion to deal with the corona virus. 2020. https://www.albawaba.com/node/sacred-soilcow-urine-and-other-rituals-people-turn-religiondeal-coronavirus-1345263 (accessed 7 May 2020).

DOI: https://doi.org/10.3399/bjgp20X709961
Pandemic preparedness starts in properly coded electronic health records

The current COVID-19 pandemic situation, similar to the increased incidence of Kaposi's sarcoma in the 1980s, exposes the relevance of surveillance of new clinical pictures, and the fact that every clinician must share the responsibility, adequately documenting consultations, and recognising that their entries will be used beyond the clinicianpatient relationship.

Clinicians' preferred use of free text to store information is inadequate. There is a need to use clinical coding extensively, not just diagnoses, but symptoms and examination findings. Otherwise electronic health records are no more than digital papers. Processing a large amount of consultations can only be made through informatics, and software works much better with coded clinical entries.

Clinicians have been using electronic records for decades but they are still infrequent coders, ${ }^{2,3}$ there is considerable data quality variation, and furthermore it is often suboptimal. ${ }^{4}$ Additional training and improving systems design are needed, ${ }^{5,6}$ but is it time to reconsider the clinical nomenclature itself? SNOMED-CT was expected to be the solution to facilitate coding, ${ }^{7}$ but clinicians are still not engaging enough with it. ${ }^{6}$ Frontline clinicians require an effortless, easy-to-use entry system that facilitates the interaction with the patient and the computer rather than the current complex and hard-to-find code nomenclature with less-than-helpful software that, combined, fail to facilitate coding consultations adequately.

The future use of clinical coding will not improve by implementing more complex nomenclatures. Currently there is more free text than code, and information will be partial, insufficient to improve health care, detrimental for research, and inefficient to alert about increases in particular symptoms or conditions.

Future generations of patients will be better served by a profound analysis of current clinical nomenclature and software, 